\title{
IMPROVEMENTS IN THE CHERS SYSTEM FOR DT EXPERIMENTS ON TFTR
}

\author{
BY \\ C.E. BUSH, R. BELL, AND E.J. SYNAKOWSKI
}

Presented at the Tenth Topical Conference on

High Temperature Plasma Diagnostics

Rochester, NY, 8-12 May, 1994

Work supported by U.S. Department of Energy Contract DE-AC02-76CHO-3073

\author{
Princeton University \\ Plasma Physics Laboratory
}

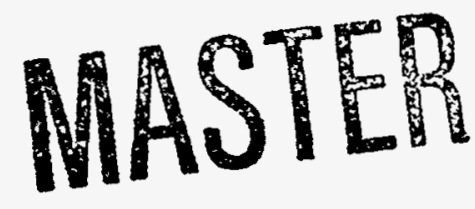




\section{DISCLAIMER}

This report was prepared as an account of work sponsored by an agency of the United States Government. Neither the United States Government nor any agency thereof, nor any of their employees, make any warranty, express or implied, or assumes any legal liability or responsibility for the accuracy, completeness, or usefulness of any information, apparatus, product, or process disclosed, or represents that its use would not infringe privately owned rights. Reference herein to any specific commercial product, process, or service by trade name, trademark, manufacturer, or otherwise does not necessarily constitute or imply its endorsement, recommendation, or favoring by the United States Government or any agency thereof. The views and opinions of authors expressed herein do not necessarily state or reflect those of the United States Government or any agency thereof. 


\section{DISCLAIMER}

Portions of this document may be illegible in electronic image products. Images are produced from the best available original document. 


\title{
Improvements in the CHERS system for DT Experiments on TFTR
}

\author{
C.E. Bush, QRNL, R.E. Bell, and E.J. Synakowski \\ Princeton Plasma Physics Laboratory \\ Princeton, NJ 08543
}

\section{Abstract}

Improvements in the charge exchange recombination spectroscopy (CHERS) system have resulted in accurate measurements of $T_{i}$ and $V_{\phi}$ profiles during $D \cdot T$ experiments. These include moving the spectrometer detector array and electronics farther away from the tokamak to a low neutron flux location. This relocation has also improved access to all components of the system. Also, a nonplasma-viewing calibration fiber system was added to monitor the change in fiber transmission due to the high flux DT neutrons. Narrowband filtered light transmitted through the calibration fiber is now used as a reference for the $V_{\phi}$ measurement. At the highest neutron flux of $\sim 2.5 \times 10^{18}$ neutrons/sec (fusion power $\sim 6.2 \mathrm{MW}$ ) a modest $5 \%$ decrease in fiber transmission was observed. Corrections for transmission loss are made and $T_{i}(r, t)$ and absolute $V_{\phi}(r, t)$ profiles are automatically calculated within four minutes of every shot.

\section{Introduction}

Charge exchange recombination spectroscopy (CHERS) [1] is being used to measure ion temperature, $T_{i}(r, t)$, and plasma toroidal velocity, $V_{\phi}(r, t)$, profiles during historic high power deuterium/tritium (DT) experiments now underway on TFTR. The measurements make use of the neutral beams used for plasma heating in order to obtain time and spatially resolved $V_{\phi}$ and $T_{i}$ data. High concentrations of tritium have been used [2]. The injected power can consist of from all $\mathrm{D}^{\circ}$ beams to 
all $\mathrm{T}^{\circ}$ beams. Although the tritium concentrations can be high, many of the interactions and physics phenomena can be fairly subtle. For example, detection of alphas and their effect on the plasma (alpha heating, TAE modes, etc.) or beam and thermal ion species effects on confinement and transport, and changes in velocity associated with supershot to H-mode transition [3] represent important physics issues; however, it may be difficult to make quantitative measurements of these effects. Accurate spatial and temporal determination of $\mathrm{V}_{\phi}$ and $\mathrm{T}_{\mathrm{i}} \mathrm{using}$ the charge exchange recombination spectroscopy technique is essential in observing and quantifying these effects.

Basic features and characteristics of the CHERS system were described in detail in earlier reports [4]. However, several modifications and changes have been made which allow new and improved measurement of $T_{i}(r, t), V_{\phi}(r, t)$, and $n_{\mathcal{C}}$ $(r, t)$ during reactor relevant DT operation. These include moving the system a long distance away from the tokamak to a location behind a concrete wall, and addition of a calibration fiber run parallel to the measurement which allows determination of the effect of neutrons on the fiber transmission [5] and a bonus capability of having a stable zero reference for the toroidal velocity measurement. A shakedown of the electronics was undertaken, and several sources of noise were eliminated, significantly improving the overall dynamic range of the system. Finally, the capability of fast high precision automatic analysis is now available and time resolved $V_{\phi}$ and $T_{i}$ profiles with fiber transmission and $V_{\phi}$ reference taken into account can be generated within four minutes after every shot.

\section{Description of Apparatus}

A schematic drawing of the CHERS system including the calibration fiber and diagnostic fiber bundles are shown in Fig. 1 as they are located relative to TFTR. The main components of the system consist of the fiber optic bundles for 
viewing the plasma and transmitting the collected light to the spectrometer. At present, there are two fiber bundles, one coming from a toroidal location at Bay $\mathrm{H}$ and the other $180^{\circ}$ away toroidally at the Bay P location. The fibers are $600 \mu \mathrm{m}$ diameter strands of pure fused silica with plastic cladding. The two bundles have double passes of calibration fiber installed directly beside them so that they sample the same neutron flux and electromagnetic environment as they traverse the distance from the viewing window to the entrance of the spectrometer. The calibration fibers begin at a position near the spectrometer where they are illuminated by a stable filtered light source; a meter away, they are placed with the two diagnostic fiber bundles. The two bundles are enclosed in two separate and opaque one inch I.D. Corelok tubes (for protection) for the full length from viewing window to spectrometer.

A tungsten lamp is the light source for the calibration fiber system. A narrow band pass optical filter which transmits at a center wavelength of $5292 \AA$ with bandwidth $\sim 4.3 \AA$ is placed between the lamp and the inlet end of the calibration fibers. The filter is placed within a well controlled oven which maintains it at a constant temperature (compensating for changes in atmospheric temperature which affect the spectral transmission of the lens). The exit ends of the calibration fibers are placed in the same vertical plane as their respective diagnostic fiber bundles. A fast switching mirror directs the light from the selected array into the spectrometer. The mirror can be programmed to switch from one bundle (Bay $\mathrm{H}$ ) to the other (Bay P) to obtain CHERS data at two toroidal positions. A co-rotating plasma moves toward the fiber array viewing the plasma at Bay $\mathrm{P}$ and away from the fiber array viewing Bay $\mathrm{H}$. During normal operation, the mirror is usually fixed to view the Bay $\mathrm{H}$ array since it provides the widest radial coverage of the plasma. The images of the diagnostic fiber array along with that of the illuminated calibration fiber are directed by the fast 
switching mirror onto the entrance slit of a $0.6 \mathrm{~m}, \mathrm{f} / 5.7$ Czerny-Turner spectrometer. At the output image plane of the spectrometer, the spectrally resolved light is imaged onto a two-dimensional intensified photodiode array (128 $\times 128$ pixel, Reticon MC9128), thus providing the spatial resolution. The system stores up to 64 frames of data during a plasma shot. Typically, the frames are taken every $20 \mathrm{~ms}$ for $1 \mathrm{sec}$ NBI heating pulses. Integration times from 10 to 100 $\mathrm{ms}$ have been used depending on the heating pulse length and the allowable time resolution.

\section{Application and Results}

The spectrometer itself, the photon/neutron sensitive diode array, and all electronics are now in a remote location where the neutron flux is reduced. The signals from the spectrometer are then transmitted to the control room where they are recorded and archived. In the original CHERS system, all of these components were located directly below the tokamak (about $5 \mathrm{~m}$ from the vacuum chamber) in the TFTR Test Cell Basement. Longer fiber bundles are now used so that the CHERS system is located $\sim 25$ meters away. The relocation of the CHERS system to a more well shielded remote location reduced the absorbed neutron dose-equivalent by greater than a factor of 70 [6]. This means significantly reduced neutron noise during a shot and reduced accumulative radiation damage to the detectors and electronics.

Another advantage of the new location is that the access to the system components, electronics, spectrometer, etc., is almost unlimited. In the old location, access was very restricted. Now under actual DT plasma operating conditions, debugging, optimization, and testing can be carried out by personnel rigint at the CHERS system location. When the spectrometer gain is increased for low plasma signal, the calibration fiber light may be too bright and saturate the 
detector. The light to the calibration fibers is adjusted accordingly by inserting neutral density filters in front of the lamp. Presently, during DD or DT operation, the filters are inserted manually.

The image or spectral/spatial data for one frame for the Bay $\mathrm{H}$ fiber array is shown in Fig. 2. The image for the calibration fiber is at the bottom of the photograph. Data for the 18 diagnostic fibers are clearly distributed vertically upward in the photograph. The fibers view the plasma through a quartz window at the midplane with each fiber aimed so as to view at 18 different tangency radii or about every $6 \mathrm{~cm}$ (from a minimum tangency radius of $2.53 \mathrm{~m}$ to a maximum of $3.51 \mathrm{~m}$ ). The Shafranov shifted plasma center (magnetic center) is typically at $2.70 \mathrm{~m}$. Figure 2 is a very good visual image of most of the imformation contained in the CHERS raw data. The vertical position represents the plasma radial position viewed, the brighter colors represent the higher light intensities, the horizontal shift of an elliptical pattern relative to the reference fiber image is indicative of $V_{\phi}$ and the horizontal width of each ellipse represents $T_{i}$. The plasma light emission is well fitted by a single Gaussian. The Doppler broadening and spectral shift are largest for the fiber at Y-pixel 100, which happens to view the center of the plasma. Thus for Fig. 2, the highest $T_{i}$ and $V_{\phi}$ are at the center of the plasma. A shift to the left of the reference fiber image indicates counter toroidal rotation. Charge exchange recombination emission from the $C^{5+} 5292 \AA$ line $(n=7-8)$ due to the interaction of the heating beam with the plasma is normally used for the CHERS measurement on TFTR.

Time resolved calibration fiber transmission data is shown in Fig. 3 for two of the highest integrated DT neutron fluxes achieved on TFTR. Also shown are the respective neutron source rates. In the first case with a 1 sec NBI pulse, the DT neutron rate is high, with a peak at $\sim 2.5 \times 10^{18}$ neutrons/sec. For the second case, the peak value is less than half this but the beam pulse is about twice as 
long. The fluctuations in the transmission data, the source of which has yet to be determined, are the same independent of whether the plasma is DD or DT. As can be seen from the figure, the total decreases in fiber transmission due to the total integrated fluxes are about the same for the two cases, $\sim 5 \%$. The peak nautron rate for the high flux example corresponds to a fusion power of 6.2 MW. For longer pulse length and/or high fusiom power, proportionally, greater transmission losses will result.

The reduction in the transmission of the diagnostics fibers should be exactly the same as that for the calibration fiber. Since there is a double loop of calibration fiber, the transmission for a single strand and thus, the single length of diagnostic fiber is $\mathrm{T} \propto \sqrt{\mathrm{I}}$, where $\mathrm{I}$ is the lamp light intensity. For each time or $\mathrm{nth}$ frame, the signal in the diagnostic fiber is $S_{n}^{\prime}=S_{n} / T_{n}$ where $\mathrm{T}_{\mathrm{n}}$ is the transmission, $S_{n}$ is the apparent signal and $S_{n}^{\prime}$ is the actual transmission corrected signal for the $\mathrm{n}^{\text {th }}$ time (frame). Error analysis for the transmission data is done at the same time and in the same manner as the $V_{\phi}$ and $T_{i}$ data [7]. The actual standard deviation is given by

$$
\sigma_{S_{n}^{\prime}}=\sqrt{S_{n}^{2}\left(\frac{\sigma_{S_{n}}^{2}}{S_{n}^{2}}+\frac{\sigma_{T_{n}}^{2}}{T_{n}^{2}}\right)}
$$

where $\sigma_{S_{n}}$ and $\sigma_{T_{n}}$ are the apparent standard variations of the signal and transmission, respectively.

Corrected $\mathrm{T}_{\mathbf{i}}$ and $\mathrm{V}_{\phi}$ profiles which make use of the calibration fiber transmission and velocity reference information are plotted in Fig. 4 along with values using an edge fiber as the reference. Alternatives to the calibration fiber as $\mathrm{V}_{\phi}$ reference are to use $5292 \mathrm{~A}$ line emission from the pre-beam ohmic plasma or for a fiber viewing the plasma edge, where $V_{\phi}$ is expected to be small, during beam 
heating. However, depending on the plasma radius, the hard mounted fiber array may not have a fiber viewing directly at the edge (the exact location of the edge is uncertain in any case) and the light emission from the ohmic plasma is weak and noisy. In Fig. 4 the reference fiber viewing the plasma edge at $3.41 \mathrm{~m}$ was chosen as the reference and the resulting data are represented by the dashed curve. The solid curve is the $V_{\phi}$ profile using the calibration fiber as the reference and are absolute rather than relative velocities. There is a significant displacement between the two curves. There are other corrections to $V_{\phi}$ which may be more important, such as for variations in the background light emission [8] and the velocity dependence of the charge exchange recombination rate. The 5\% decrease in fiber transmission for the plasma of Fig. 3 was found to result in a maximum correction at $\mathrm{T}_{\mathrm{i}} \sim 27 \mathrm{keV}$ of $\sim 0.5 \mathrm{keV}$ or $2 \%$. Similarly, as for $\mathrm{T}_{\mathfrak{i}}$, , corrected profiles for $V_{\phi}$ and the plasma carbon light intensity are also available.

This work was supported by the U.S. Department of Energy Contract No.

DE-AC02-76-CHO-3073. 


\section{References}

[1] R.J. Fonck, D.S. Darrow, and K.P. Jaehnig, Phys. Rev. A 29, 3288 (1984).

[2] R.J. Hawryluk, H. Adler, P. Alling, et al., Princeton Plasma Physics Laboratory Report No. PPPL-2987 (April 1994). Accepted for publication.

[3] C.E. Bush, N. Bretz, R. Nazikian, et al., Princeton Plasma Physics Laboratory Report No. PPPL-2863, submitted to Nucl.Fusion; C.E. Bush, R.J. Goldston, et al., Phys. Rev. Lett. 65, 424 (1990).

[4] B.C. Stratton, R.J. Fonck, K.P. Jaehnig, N. Schechtman, E.J. Synakowski, Princeton Plasma Physics Laboratory Report No. PPPL-2745 (March, 1991).

[5] A.T. Ramsey and K.W. Hill, Rev. Sci. Instrum. 63, 4744 (1992).

[6] H. Kugel, private communication.

[7] R.E. Bell, D.W. Johnson, B.C. Stratton, and E.J.Synakowski, Rev. Sci. Instrum. 63, 4744 (1992).

[8] E.J. Synakowski, R.E. Bell, C.E. Bush, this conference. 


\section{Figure Captions}

FIG. 1. Schematic drawing showing the CHERS system in its new remote location. The two fiber array bundles and their sightlines as they intersect heating beam paths are indicated.

FIG. 2. Image in fiber position vs. wavelength space of the output from the 2-D intensified photodiode array located at the exit end of the Czerny Turner spectrometer. The calibration fiber is at the bottom and the 18 diagnostic fibers are distributed vertically upward on the screen.

FIG. 3. (a) DT neutron emission for two different plasma heating pulses, a short how power pulse ( fusion $\sim 6.2 \mathrm{MW}$ ) and a long medium pulse (b) give evolutionof the fiber transmission for the two cases.

FIG. 4. $T_{i}$ profile at $t=3.75 \mathrm{~s}$ for the high power / high neutron rate DT plasma of Fig. 2. The correction in the peak $\mathrm{Ti}(\sim 27 \mathrm{keV})$ for a $5 \%$ decrease in fiber transmission is $500 \mathrm{ev}$; extrapolation to 10 and $20 \%$ decreases in fiber transmission indicate corrections of 1 and $2 \mathrm{keV}$ respectively. 

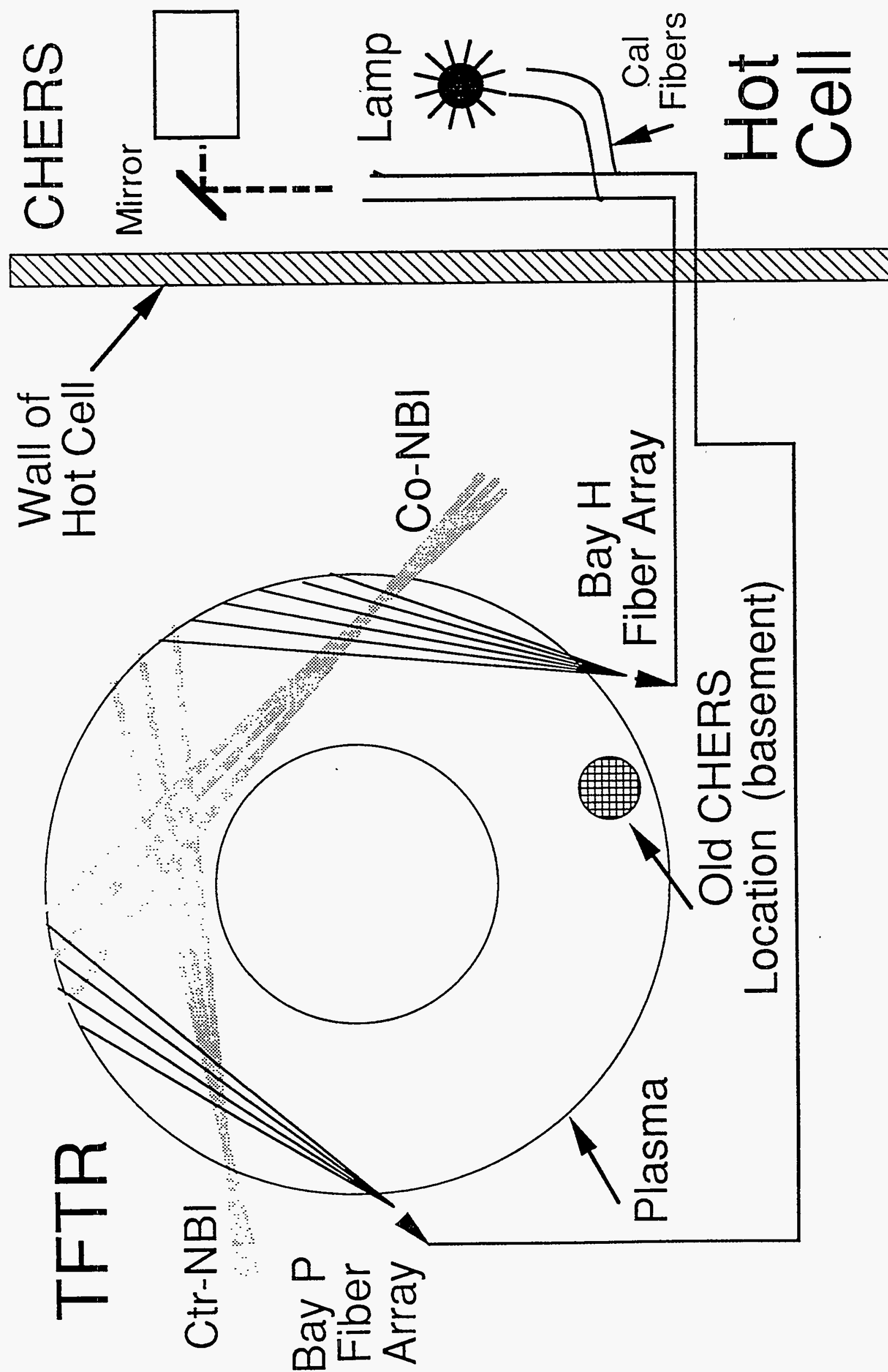


\section{CHERS $\mathrm{V}_{\phi}$ and $\mathrm{T}_{\mathbf{i}}$ Data for TFTR Shot \# 75963}

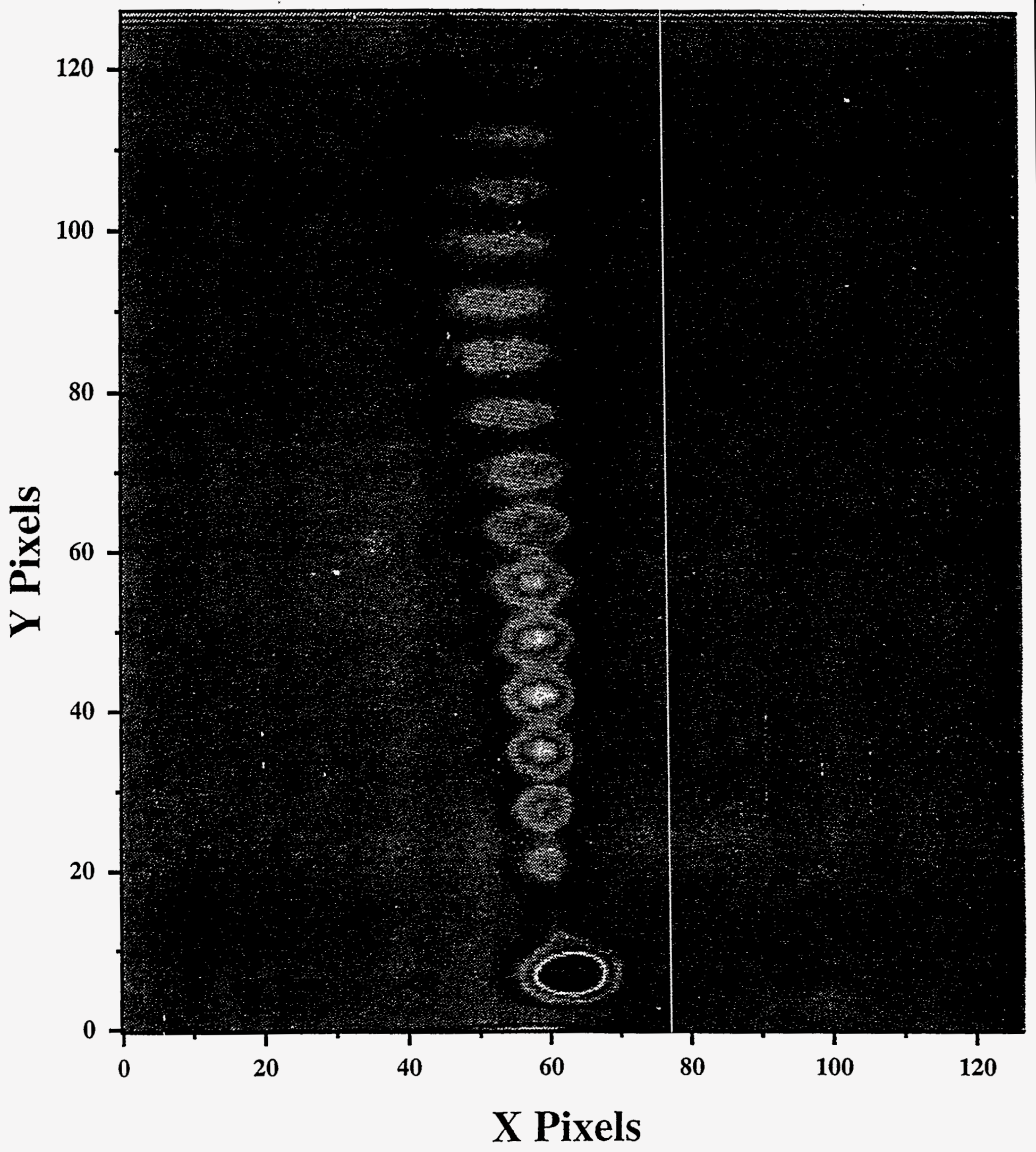



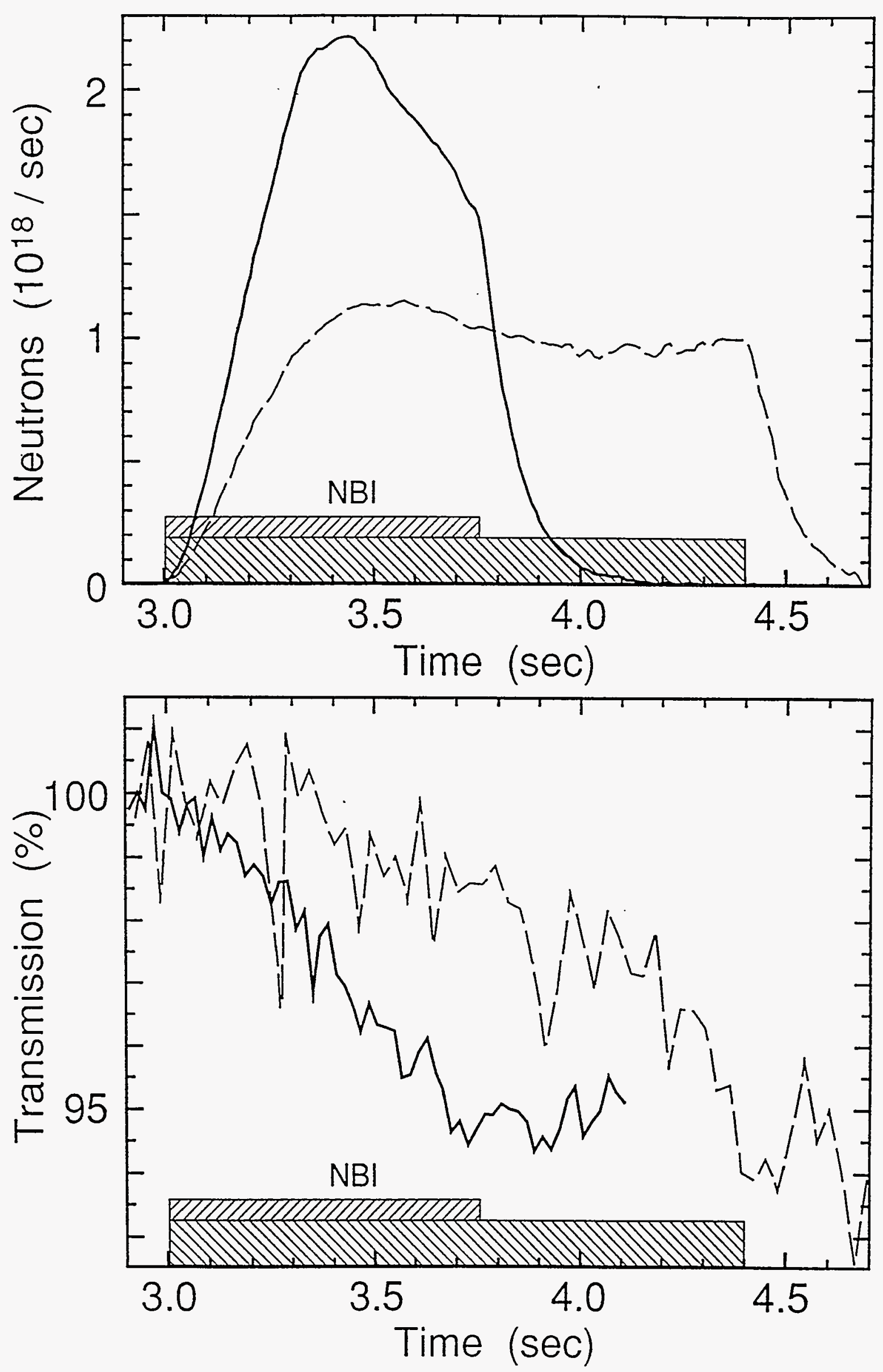


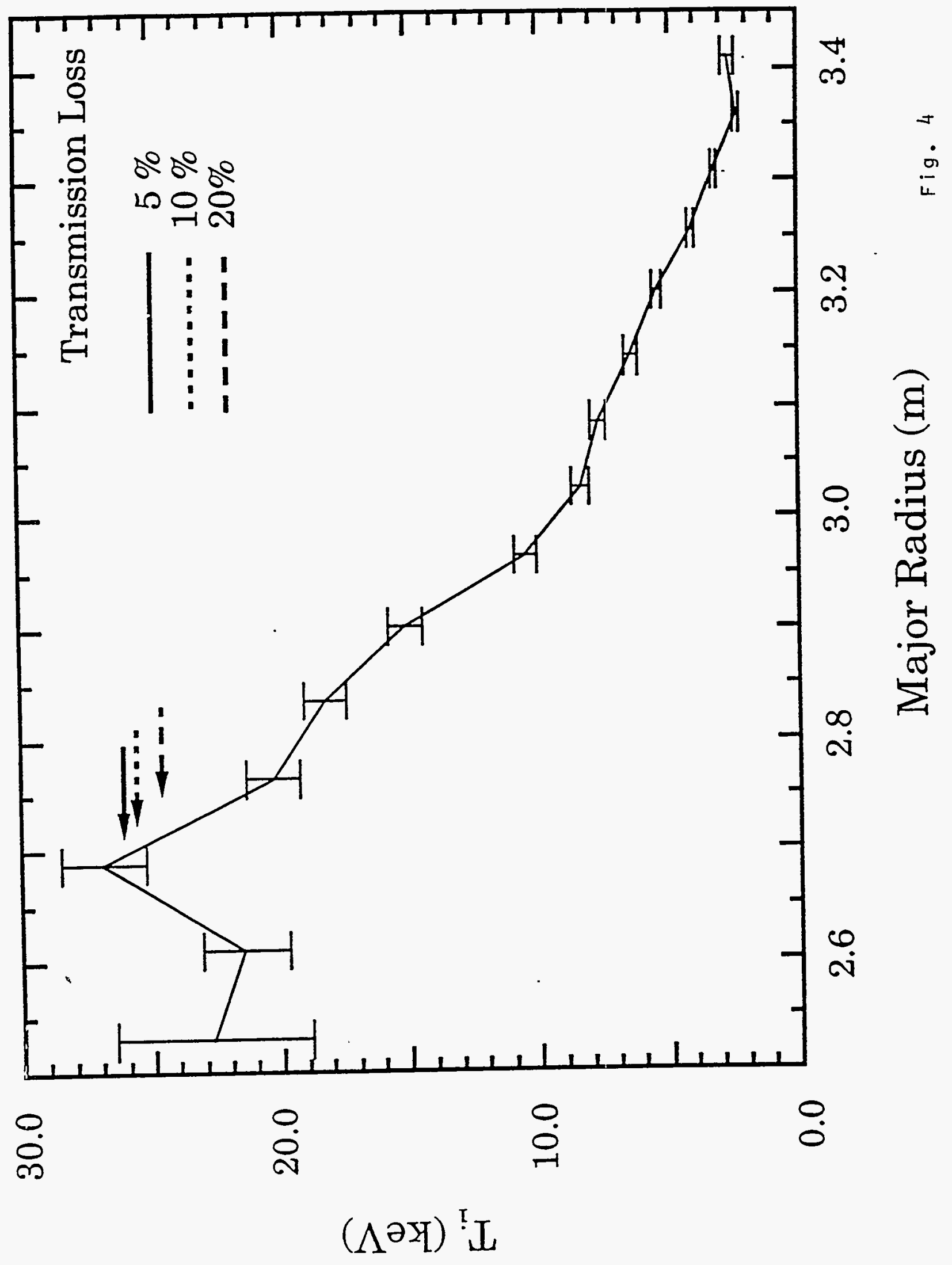




\section{EXTERNAL DISTRIBUTION IN ADDITION TO UC-420}

Dr. F. Paoloni, Univ. of Wollongong, AUSTRALIA

Prof. R.C. Cross, Univ. of Sydney, AUSTRALIA

Plasma Research Lab., Australian Nat. Univ., AUSTRALIA

Prof. I.R. Jones, Flinders Univ, AUSTRALIA

Prof. F. Cap, Inst. for Theoretical Physics, AUSTRIA

Prof. M. Heindler, Institut für Theoretische Physik, AUSTRIA

Prof. M. Goossens, Astronomisch Instituut, BELGIUM

Ecole Royale Militaire, Lab. de Phy. Plasmas, BELGIUM

Commission-European, DG. XII-Fusion Prog., BELGIUM

Prof. R. Bouciqué, Rijksuniversiteit Gent, BELGIUM

Dr. P.H. Sakanaka, Instituto Fisica, BRAZIL

Prof. Dr. I.C. Nascimento, Instituto Fisica, Sao Paulo, BRAZIL Instituto Nacional De Pesquisas Espaciais-INPE, BRAZIL

Documents Office, Alomic Energy of Canada Ltd., CANADA

Ms. M. Morin, CCFMTokamak de Varennes, CANADA

Dr. M.P. Bachynski, MPB Technologies, Inc., CANADA

Dr. H.M. Skarsgard, Univ. of Saskatchewan, CANADA

Prof. J. Teichmann, Univ. of Montreal, CANADA

Prof. S.R. Sreenivasan, Univ. of Calgary, CANADA

Prof. R. Marchand, INRS-Energie et Materiaux, CANADA

Dr. R. Bolton, Centre canadien de fusion magnétique, CANADA

Dr. C.R. James, Univ. of Alberta, CANADA

Dr. P. Lukác, Komenského Universzita, CZECHO-SLOVAKIA

The Librarian, Culham Laboratory, ENGLAND

Library, R61, Rutherford Appleton Laboratory, ENGLAND

Mrs. S.A. Hutchinson, JET Library, ENGLAND

Dr. S.C. Sharma, Univ. of South Pacific, FIJI ISLANDS

P. Mähönen, Univ. of Helsinki, FINLAND

Prof. M.N. Bussac, Ecole Polytechnique, FRANCE

C. Mouttet, Lab. de Physique des Milieux lonisés, FRANCE

J. Radet, CEN/CADARACHE - Bat 506, FRANCE

Prot. E. Economou, Univ. of Crete, GREECE

Ms. C. Rinni, Univ. of loannina, GREECE

Preprint Library, Hungarian Academy of Sci., HUNGARY

Dr. B. DasGupta, Saha Inst. of Nuclear Physics, INDIA

Dr. P. Kaw, Inst. for Plasma Research, INDIA

Dr. P. Rosenau, Israel inst. of Technology, ISRAEL

Librarian, International Center for Theo Physics, ITALY

Miss C. De Palo, Associazione EURATOM-ENEA , ITALY

Dr. G. Grosso, Istituto di Fisica del Plasma, ITALY

Prof. G. Rostangni, Istituto Gas lonizzati Del Cnr, ITALY
Dr. H. Yamato, Toshiba Res \& Devel Center, JAPAN

Prof. I. Kawakami, Hiroshima Univ., JAPAN

Prof. K. Nishikawa, Hiroshima Univ., JAPAN

Librarian, Naka Fusion Research Establishment, JAERI, JAPAN

Director, Japan Atomic Energy Research inst., JAPAN

Prof. S. Itoh, Kyushu Univ., JAPAN

Research Info. Ctr., National Instit. for Fusion Science, JAPAN

Prof. S. Tanaka, Kyoto Univ., JAPAN

Library, Kyoto Univ., JAPAN

Prof. N. Inoue, Univ. of Tokyo, JAPAN

Secretary, Plasma Section, Electrotechnical Lab., JAPAN

Dr. O. Mitarai, Kumamoto Inst. of Technology, JAPAN

Dr. G.S. Lee, Korea Basic Sci. Ctr., KOREA

J. Hyeon-Sook, Korea Atomic Energy Research Inst., KOREA

D.I. Choi, The Korea Adv. Inst. of Sai. \& Tech., KOREA

Prof. B.S. Liley, Univ. of Waikato, NEW ZEALAND

Inst of Physics, Chinese Acad Sci PEOPLE'S REP. OF CHINA

Library, Inst. of Plasma Physics, PEOPLE'S REP. OF CHINA

Tsinghua Univ. Library, PEOPLE'S REPUBLIC OF CHINA

Z. Li, S.W. Inst Physics, PEOPLE'S REPUBLIC OF CHINA

Prof. J.A.C. Cabral, Instituto Superior Tecnico, PORTUGAL

Prof. M.A. Hellberg, Univ. of Natal, S. AFRICA

Prof. D.E. Kim, Pohang Inst. of Sci. \& Tech., SO. KOREA

Prof. C.I.E.M.A.T, Fusion Division Library. SPAIN

Dr. L. Stenflo, Univ. of UMEA, SWEDEN

Library, Royal Inst. of Technology, SWEDEN

Prof. H. Wilhelmson, Chalmers Univ. of Tech., SWEDEN

Centre Phys. Des Plasmas, Ecole Polytech, SWITZERLAND

Bibliotheek, Inst. Voor Plasma-Fysica, THE NETHERLANDS

Asst. Prof. Dr. S. Cakir, Middle East Tech. Univ., TURKEY

Dr. V.A. Glukhikh,Sci. Res. Inst. Electrophys.I Apparatus, USSR

Dr. D.D. Ryutov, Siberian Branch of Academy of Sci., USSR

Dr. G.A. Eliseev, I.V. Kurchatov Inst, USSR

Librarian, The Ukr.SSR Academy of Sciences, USSR

Dr. L.M. Kovrizhnykh, Inst. of General Physics, USSR

Kemforschungsanlage GmbH, Zentralbibliothek, W. GERMANY Bibliothek, Inst. Fur Plasmaforschung, W. GERMANY

Prof. K. Schindler, Ruhr-Universitát Bochum, W. GERMANY

Dr. F. Wagner, (ASDEX), Max-Planck-Institut, W. GERMANY

Librarian, Max-Planck-Institut, W. GERMANY 